\title{
How Calculative are Managers When Evaluating Signals? An Empirical Examination of Signaling Theory in Trust Formation
}

\author{
Pook Carson \\ Associate Professor \\ Department of Business Management \\ Salt Lake Community College
}

\begin{abstract}
In this research, we examine how calculative managers are when deciding whether or not to trust a channel partner. We distinguish between fully-calculative, non-calculative, and signaling models of trust formation based on credibility. The results show that interpretations of cooperative and non-cooperative actions are influenced by credibility. Credibility overwhelms past history in that the history (number) of positive interactions has no effect on trust when there is at least one credible signal. Partner replaceability decreases the level of trust from credible signals as subjects attribute the cooperative behavior to external market incentives rather than type. While participants attend to credibility, they do not distinguish between signals in the form of past behavior and signals created by credible commitments to bonds regulating incentives for future behavior. Hence, managers are more calculative than current non-calculative theories of trust would suggest, but less rational and less forwardlooking than predicted by strong-form fully-calculative approaches.
\end{abstract}

Keywords: Trust, signaling, credibility, calculative and non-calculative approaches to trust, interorganizational relationships, cooperation

\section{Introduction}

The need to evaluate indications regarding the trustworthiness of current and potential partners is central to the formation of trust in interorganizational relationships (Ring and Van de Ven 1992; Doz 1996). In this paper, we use signaling theory to gain insight into trust development while simultaneously examining the assumptions of rationality at the heart of the theory. In particular, we consider the conditions under which indications in the form of past cooperative behavior are an accurate basis for trust development and examine the extent to which they are relied upon by practicing managers. We discuss the role of credibility in trust formation and test theoretical predictions derived from signaling theory against both more and less calculative alternatives in a laboratory experiment.

Signaling theory is a distinct branch of economics, having grown out of the information economics area (Stigler 1961) and playing a prominent role in the adverse selection or hidden information branch of agency theory (Rothschild and Stiglitz 1978). The focus of the theory is on indications-potential signals — offered by one party to another that may or may not convey accurate information. The principle issue is whether these indications of future cooperative intentions are credible in the sense that they can be relied upon to accurately inform expectations (Akerloff 1970; Nelson 1974; Ross 1973; Spence 1973). Credible signals are differentiated from non-credible indications - colorfully referred to as cheap talk in the literature-which are not accurate indicators of future intentions. ${ }^{1}$

To date, very little has been done in the signaling literature to address trust formation per se (Wang, Beatty, and Foxx 2004). This is due in large part to the maintained assumption of self-interest seeking which has led to a focus on more concrete attributes of products (e.g., quality) and individuals (e.g., ability) rather than trustworthiness. The essential distinction is that economic theories usually presume all parties to be self-interested and thus non-cooperative absent specific incentives to the contrary. Yet the core logic of the theory transfers easily once differences in individual predispositions are accepted.

\footnotetext{
${ }^{1}$ In the economics literature, the term signal is used only in reference to credible indications. We follow this convention. 54
} 
Hence, while we extend the core signaling logic to the literature on trust formation, we also examine the extent to which parties can signal trustworthiness at all and whether credibility matters in this context.

According to signaling theory, cooperative behavior in the past may be either a credible or non-credible indicator of future cooperative intentions depending on the circumstances surrounding the prior exchange. The idea that past cooperative behavior is not always a credible signal of trustworthiness is at the heart of our empirical investigation. On this issue, a distinct split is observed in the extant literature over how past cooperative actions should be interpreted. Calculative theories of the kind common in economics largely discount past behavior (both cooperative and non-cooperative), preferring instead to focus on incentives for cooperation in future exchanges (e.g., Williamson 1993; Sitkin and Roth 1993; Sako and Helper 1998). Non-calculative approaches, in contrast, place a much heavier emphasis on past behavior as a basis of trust formation (e.g., Ring and Van de Ven 1994). Under this more process-based perspective (e.g., Zucker 1986), "trust changes over time- developing, building, declining and even resurfacing in long-standing relationships (Rousseau et al. 1998, p 395)." While noncalculative theories are closely related to sociological approaches, a focus on past behavior is not unique to this paradigm. Indeed, signaling models also look to past behavior to indicate type. As we explain below, despite this similarity to non-calculative theories and, on the calculative side, a generally rational worldview, signaling theory differs from both approaches to trust in important ways.

In the experiment presented below, interpretations of both cooperative and non-cooperative actions are shown to be significantly influenced by credibility. Credibility overwhelms the effect of past history in the sense that the history (number) of positive interactions has no effect on trust when parties have recourse to at least one credible signal. Surprisingly, partner replaceability is shown to decrease the level of trust resulting from credible signals; subjects attribute the cooperative behavior to external market incentives rather than type and do not increase their reported trust in their partner. While participants attend to credibility in the study, they do not distinguish between signals in the form of past behavior and signals created by credible commitments to bonds regulating incentives for future behavior. Hence, managers are more calculative than current non-calculative theories of trust would suggest, but less rational and less forward-looking than predicted by strong-form calculative approaches.

This paper is organized as follows. In the next section, we review the literature on trust formation and compare signaling theory to extant calculative and non-calculative alternatives in the trust literature. We then present an experiment designed to examine the role of credible signals in trust formation. Finally, we discuss the results and implications for theory and practice.

\section{Conceptual Background and Theory Development}

Trust has been shown to have a significant effect on behavior and performance in interorganizational relationships (Zaheer, McEvily, and Perrone 1998). Trust reduces transaction costs (Mohr and Spekman 1994) and increases adaptability, making it especially important in highly uncertain or potentially adversarial relationships. Trust can be defined succinctly as expectations of positive behavior that one party holds about another (Ring and Van de Ven 1992). In the context of interorganizational relationships, the desired positive behavior usually takes the form of cooperation during ex post adjustments (Zucker 1986; Gambetta 1988; Sako 1992; Mayer et al. 1995). Trusted parties are expected to take a long-term perspective and act in the mutual interest of both firms during such adjustments (i.e., forbearance) rather than give in to short-term incentives for opportunistic behavior (Rousseau et al. 1998). As discussed in detail by Rousseau et al. (1998), risk is the sin qua non of trust in that expectations for positive behavior may prove incorrect. Thus, careful evaluations of trustworthiness are central to trust formation and parties will look for ways to evaluate signals regarding the cooperative intentions of current and potential partners.

The extant literature highlights a number of influences on trust formation. The history of interactions between firms, social ties, common backgrounds, shared cultural identity, mutually-oriented values, benevolence and integrity, a propensity to trust in others, competencies, reputations, and incentives have all been posited to impact trust (see, e.g., Mayer, Davis and Schoorman, 1995, for a review). The theoretical approaches that advance these arguments may be categorized in a variety of ways (Rousseau et al. 1998). For our purposes, the most useful distinction is between calculative (structural) and non-calculative (relational) approaches to trust (Hosmer 1995; McKnight, Cummings, and Chervany 1998; Poppo and Zenger 2002; Moran 2005). As we discuss below, these distinctions are to a large extent blurred by signaling theory; nevertheless, they are useful in understanding how the theory adds to extant perspectives. 
Calculative approaches to trust are rooted in economic theory. Calculative trust is based on forward-looking evaluations of incentives to behave in a desirable manner (Williamson 1993). ${ }^{2}$ From a calculative perspective, parties are trusted to the extent that incentives for cooperation are expected to exist in future exchanges. As a result of this forward-looking orientation, issues such as reputations and repeated exchange come to the fore as institutions that create incentives for cooperative behavior (Macneil 1980, 1982). Both serve as hostages or bonds which are jeopardized by non-cooperative behavior, making cooperation self-enforcing and resulting in trust (Williamson 1993).

Non-calculative trust, in contrast, is more sociological in nature and largely backward-looking. Non-calculative approaches view trust as originating primarily from a past history of positive interactions. More trusted partners are those with which the individual or firm has had a series of exchanges resulting in beneficial outcomes (e.g., Ring and Van de Ven 1994; Doz 1996). Coming to know and understand the type of person or organization one is dealing with through these interactions is central to most non-calculative theories of trust. This stands in sharp contrast to calculative perspectives that eschew the notion of type and focus more squarely on incentives.

Signaling theory blends calculative and non-calculative perspectives in a way which makes it unique and different from both. In contrast to calculative approaches, signaling theory acknowledges the importance of discerning type based on past behavior in a manner similar to non-calculative treatments. That is, signaling theory is not focused solely on future incentives for behavior. However, the theory differs from non-calculative approaches in that it is far more analytic in its evaluations of past behavior. In particular, cooperative behaviors consistent with selfinterests are discounted as indicators of future trustworthiness since they carry no actual or potential cost and are thus a form of cheap talk. In this sense, signaling theory gives particular weight to past behaviors inconsistent with short-term self-interests, although the issuance of such signals must be rational in the long-term.

For a signal to be credible, two conditions must be met. First, the signal must involve some cost or potential cost or it must be verifiable (Milgrom and Roberts 1986). Since verification of intentions (in contrast to certain abilities or competencies) is quite problematic, costliness becomes the key concern. By cost we refer to either an explicit cost or an opportunity cost. Signals which carry no cost (or potential cost in the event of defection) cannot be credible indications of trustworthiness since they cannot be distinguished from cheap talk. Second, credible signals must be incentive compatible in the sense that they are less costly in the long-run for parties of the type indicated by the signal than for parties of different types. The latter condition specifies what is known as a separating or partitional equilibrium (Spence 1973) in which different firms have incentives to self-select different actions that accurately indicate their type.

A classic example of a credible signal and a separating equilibrium can be found in the signaling literature on education (Spence 1973). According to this theory, higher education is of value not because students necessarily learn useful skills (a provocative claim), but because it serves as a signal of high student capability to potential employers. Education is a credible signal of high capability because, while both high and low capability students can potentially earn a degree, the process is less costly for more capable students. Higher capability students are also more likely to hold their jobs and reap the long-term benefits of their education. Thus, they are more likely to issue the signal than less capable students, and the signal is separating.

In this study, we focus on two potential signals: (1) cooperative behavior that carries a short-term cost and (2) actions that commit a party to a bond subjecting them to a cost conditional on future non-cooperation or defection. The latter is clearly separating in that it carries no costs (other than transaction costs) for cooperative firms while imposing costs on firms of a non-cooperative type. The former will also generally satisfy the conditions for a separating equilibrium in either or both of two ways. First, cooperation is more incentive compatible for firms which hold mutually-oriented preferences. Hence, firms of a cooperative type will find the cooperative behaviors involved in issuing the signal less costly per se than non-cooperative firms. Second, like education, the benefits of cooperative behavior are generally realized over an extended period of future interactions.

\footnotetext{
${ }^{2}$ Evaluations of the competencies needed to act in a desirable manner are also a common theme in the calculative literature. Our focus in this research is on incentives and predispositions for cooperation rather than competence. Readers interested in competence will note that the signaling literature on education and employment addresses this issue in some detail (Spence 1973). 
Since truly cooperative firms can expect longer-term relationships, initial cooperative signals are less costly in the long-run (or not costly at all) for firms of a cooperative type than for non-cooperative firms falsely issuing the signal. Note that this is the same argument used in the signaling literature to establish the credibility of advertising or investments in brand equity as signals of product quality - these costly signals are only rational if the firm expects repeat purchases due to its (private) information about product quality that will allow it to recover its large initial investment (Nelson 1974).

Signaling theory thus qualifies the kinds of behaviors that should influence trust formation. In particular, overtly cooperative behaviors that do not carry a cost or potential cost are not credible signals of trustworthiness since they are in the best interest of the issuing firm regardless of future intentions. It is an open empirical question as to the role costliness will play for actual managers in qualifying their interpretations of past cooperative actions. Moreover, it is unclear whether these managers will place greater emphasis on past behavior or future incentives when deciding whether to trust. From a fully-calculative perspective, signals in the form of past actions should be discounted in favor a consideration of future incentives, as described above. Hence, neither costly nor non-costly past behavior should impact trust formation. Under this view, only actions which commit parties to future losses in the event of non-cooperative behavior would be credible signals of intentions to cooperate. Such signals take the form of hostages or bonds which impact future incentives by inflicting a loss on the actor should it behave non-cooperatively. We investigate this more calculative signal below and use the term bond to differentiate this kind of signal from costly past behavior.

\section{Experiment}

We recruited experienced managers through a professional social network and asked them to indicate their level of trust in a hypothetical business partner after observing how it behaved. We selected supplier relationships as the basis for the experimental scenarios since they are common, relevant to trust, and easily approached by managers with diverse backgrounds. In each experimental cell, the participating manager is presented with a scenario in which the partner (supplier) behaves either cooperatively or non-cooperatively in response to a request for an ex post adjustment. We manipulate the context to make the behavior either credible by virtue of bring costly, non-credible (non-costly), or a commitment to a bond. We further manipulate the past history between the firms to investigate this key distinction between signaling and non-calculative approaches. We also investigate the role of supplier replaceability to see if it adds to trust beyond the effect of credible past behavior.

The experiment takes the form of a mixed-factorial within-subjects design with four factors (cooperative/noncooperative, credible/non-credible/bond, no history/history, non-replaceable/replaceable). There are a total of eight cells. Given the expected power of the stimuli and the difficulty of recruiting practicing managers, we targeted 20 evaluations of trust per cell. To recruit participants, we began by identifying 30 practicing managers with at least 10 years of full-time managerial experience and ties to our institution who were asked to participate in the study. Ultimately, 19 managers agreed to participate and completed the questionnaire. Each manager responded to the eight different scenarios yielding 152 separate evaluations of trust. The order of the scenarios was randomized across participants to counterbalance order effects. The experimental cells are described in Table 1. The instructions and scenarios presented in each cell are given in the Appendix.

TABLE 1 Scenarios

\begin{tabular}{|l|l|l|l|l|l|}
\hline Scenario & $\begin{array}{l}\text { Cost of } \\
\text { Adjustment (to } \\
\text { Supplier) }\end{array}$ & $\begin{array}{l}\text { Revenue Gain } \\
\text { from Making } \\
\text { Adjustment } \\
\text { (to Supplier) }\end{array}$ & $\begin{array}{l}\text { Supplier } \\
\text { Cooperates? }\end{array}$ & $\begin{array}{l}\text { Supplier } \\
\text { Replaceable? }\end{array}$ & $\begin{array}{l}\text { Past History } \\
\text { of } \\
\text { Cooperation? }\end{array}$ \\
\hline 1 & 150,000 & 100,000 & Yes & No & No \\
\hline 2 & 100,000 & 150,000 & Yes & No & No \\
\hline 3 & 150,000 & 100,000 & No & No & No \\
\hline 4 & 100,000 & 150,000 & No & No & No \\
\hline 5 & 150,000 & 100,000 & Yes & Yes & No \\
\hline 6 & 100,000 & Bond & Yes & No & No \\
\hline 7 & 100,000 & 150,000 & Yes & No & Yes** \\
\hline 8 & 150,000 & 100,000 & Yes & No & Yes** \\
\hline
\end{tabular}

* Gain is 150,000 if cooperative; 100,000 if non-cooperative in the future.

** Supplier behaved the same way on five previous occasions. 
The "baseline" scenario (Scenario 2) is one in which the supplier behaves cooperatively in response to the request. The adjustment makes the supplier better off in the short-term, hence the cooperation carries no cost and is thus non-credible. Trust is most relevant in relationships where the supplier is not replaceable; otherwise the threat of replacement creates a self-enforcing tendency toward cooperation. Hence, subjects are told that the supplier is non-replaceable in all cells except those where we specifically investigate the influence of replaceability. Finally, the baseline scenario features a short history of a single interaction during which behavior is observed. Other cells differ from the baseline in one or more ways corresponding to the experimental manipulations.

Subjects complete a single psychometric trust scale after observing the scenario. The items in the trust scale (Table 2) measure whether the subject expects the supplier to behave in a cooperative, mutually-oriented manner in the future. The trust score is formed by summing the scores on the items in Table 2. The psychometric properties of the scale appear to be acceptable with a Cronbach's Alpha of .962 indicating a high degree of internal consistency among the items in the scale.

\section{TABLE 2 Measurement Scale for Trust}

Please indicate what type of supplier you think you are dealing with in this scenario:

\begin{tabular}{|c|c|c|c|c|c|c|c|c|}
\hline cooperative & 7 & 6 & 5 & 4 & 3 & 2 & 1 & uncooperative \\
\hline trustworthy & 7 & 6 & 5 & 4 & 3 & 2 & 1 & untrustworthy \\
\hline $\begin{array}{l}\text { concerned with } \\
\text { our profitability }\end{array}$ & 7 & 6 & 5 & 4 & 3 & 2 & 1 & $\begin{array}{l}\text { unconcerned with } \\
\text { our profitability }\end{array}$ \\
\hline generous & 7 & 6 & 5 & 4 & 3 & 2 & 1 & selfish \\
\hline willing to help & 7 & 6 & 5 & 4 & 3 & 2 & 1 & unwilling to help \\
\hline $\begin{array}{r}\text { concerned about } \\
\text { how we both } \\
\text { perform }\end{array}$ & 7 & 6 & 5 & 4 & 3 & 2 & 1 & $\begin{array}{l}\text { concerned only } \\
\text { about how they } \\
\text { perform }\end{array}$ \\
\hline
\end{tabular}

\section{Hypotheses}

According to signaling theory, cooperative past behavior should only affect trust if it is credible (Spence 1973). Cooperative but non-costly behaviors are not credible signals of type, and should be discounted if signaling theory accurately describes the formation of trust. This is the key distinction between signaling and less calculative approaches to trust formation, as reviewed above.

Hypothesis 1: Credible (costly) past cooperative behavior will be associated with greater trust than non-credible (non-costly) past cooperative behavior. ${ }^{3}$

Actions which create future incentives or bonds against non-cooperative behavior are also credible indicators of trustworthiness. Such actions are required by more calculative theories of trust formation. We first hypothesize that bonds will be associated with higher trust relative to the non-credible baseline scenario.

Hypothesis 2: Bonds will be associated with greater trust than non-credible (non-costly) past cooperative behavior.

Second, we compare credible past behavior with the bond. Signaling theory views actions which create bonds as credible, but does not suggest any greater impact on trust than other credible indicators, such as costly past behavior. Hence, the key distinction between signaling theory and more calculative approaches to trust formation is that, according to signaling theory, bonds should have no greater impact on trust formation than any other type of credible signal. This would suggest that subjects are not hyper-calculative or hyper-rational per more calculative approaches. Substantively, the difference comes from the recognition of "type" in signaling theory which is not recognized by the more calculative alternatives.

Hypothesis 3: Bonds will not be associated with greater trust than credible (costly) past cooperative behavior.

\footnotetext{
${ }^{3}$ It is possible that the dollar amounts in our experimental stimuli are insufficient for subjects to view the costs as credible. In particular, subjects may view them as insufficient to create a separating equilibrium. If true, however, this would produce effects which fail to support the hypotheses, in contrast to what we observe below. Hence we judge the values sufficient to be credible.
} 
Signaling theory does not attach greater credibility to a longer past history of cooperation per se (Radner 1981). This differs from non-calculative approaches that view the extent of past history as the most important variable parameterizing the degree of trust formation. From a signaling perspective, history should matter less than credibility.

A strong-form interpretation of this theory would posit that history does not matter at all. However, we opt for a more nuanced position. When cooperative acts are credible by virtue of being costly, we do not expect past history to matter in the sense of further increasing evaluations of trustworthiness beyond the effects of credibility. Essentially, they are redundant. However, when the cooperative acts themselves are non-costly and thus do not afford the opportunity to credibly signal trustworthiness, we leave open the possibility that the length of past history will matter to our practicing managers. That said, if credible information is available, signaling theory suggests that subjects should rely on it more than history:

Hypothesis 4: A longer history of past cooperative behavior will not be associated with greater trust than a shorter history in situations where the cooperative behavior is credible (costly). In contrast, a longer past history of cooperative behavior will be associated with greater trust than a shorter history in situations where the cooperative behavior is non-credible (non-costly).

We also consider the role costliness plays in interpreting non-cooperative behavior. While the signaling literature generally assumes that both credible signals and cheap talk consist of overtly cooperative (positive) behavior, the damage done to trust by non-cooperative behavior may be influenced by the costliness of (forgone) cooperation. In contrast to the cooperative case, where costly behavior has a larger effect on trust than non-costly behavior, non-cooperative behavior should reflect more negatively on character when cooperation would carry little cost. Hence, we expect non-cooperative behavior to negatively influence trust to a greater extent if cooperation would be non-costly than if it would be costly. In this sense, non-cooperation becomes a more "credible" signal if cooperation would carry little cost:

Hypothesis 5: Non-cooperative past behavior will have a more negative impact on trust when cooperation would be non-costly than when cooperation would be costly.

Finally, future incentives for cooperation can be created by market forces if the supplier is easily replaced (Williamson 1985). Indeed, the trust literature seems to assume that market forces do not create self-enforcing cooperative outcomes, else the importance of trust would be severely discounted. In practice, this assumption is relatively benign, since most relationships involve a degree of co-specialization or bi-lateralism that makes replacement costly. This is true even of relationships that start out as non-specialized competitive market transactions per Williamson's (1985) fundamental transformation. That said, an interesting question concerns how replaceability affects evaluations of trustworthiness. Calculative theories would suggest that replaceability (like a commitment to a bond) should increase trust due to its effect on incentives. Thus, credible past cooperative behavior should generate even higher levels of trust if the partner is also replaceable. However, an alternative possibility is that boundedly rational managers will attribute the cooperative behavior to replaceability rather than type, which could actually result in lower trust of the partner. In particular, unlike the case of a bond where a partner is observed to voluntarily enter into an incentive arrangement (i.e., credibly revealing type), replaceability does not involve a directly observable volitional action. Moreover, trust based on replaceability requires confidence that external incentives will remain in effect over a prolonged period. In practice, boundedly-rational managers may rely less on amorphous market incentives when deciding to trust than on more immediate signals of type. Hence:

Hypothesis 6: Credible (costly) cooperative behavior will be associated with lower trust when the supplier is replaceable than when it is not replaceable.

\section{Results}

The hypotheses are tested through a series of planned comparisons in an ANOVA $(\mathrm{F}=35.302 ; \mathrm{p}<.001)$. We use one-tail hypothesis tests for a priori directional hypotheses. The dependent variable is trust, calculated as the sum of scores on the six items in the trust scale. The average for each cell is given graphically in Figure 1. 


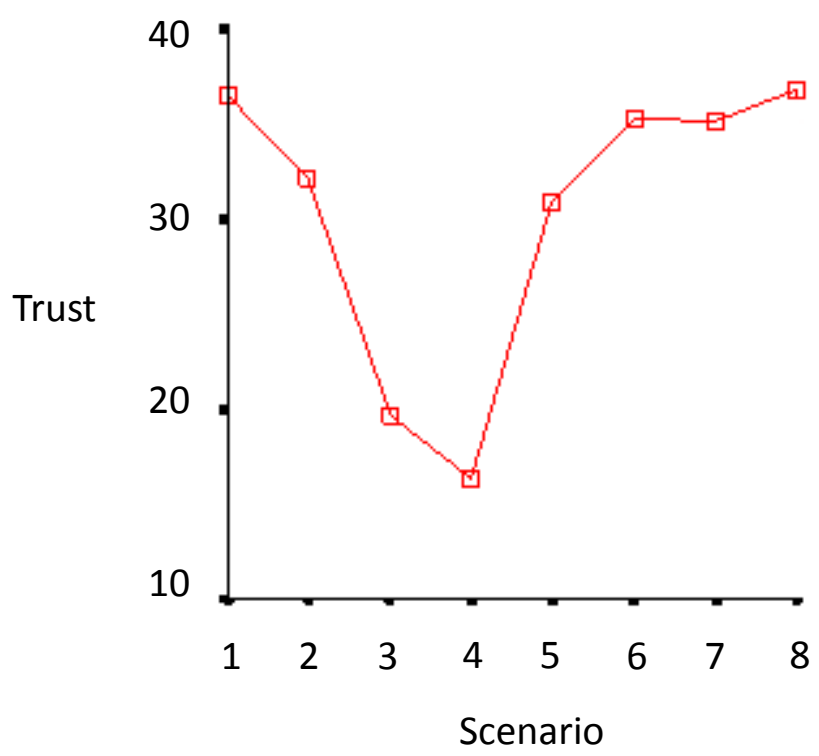

Hypothesis 1 is supported by the contrast between the cooperative/non-costly baseline Scenario 2 and the cooperative/costly Scenario $1\left(\mathrm{M}_{1}-\mathrm{M}_{2}=5.105 ; \mathrm{p}=.005\right)$. Cooperative past behavior which is costly to the supplier is associated with greater trust than cooperative but non-costly past behavior, as hypothesized. This suggests that credibility matters when evaluating past cooperative behavior, consistent with the core insight from signaling theory. Cooperative behavior per se is not as important as behavior that credibly reveals cooperative type by virtue of being costly.

Hypothesis 2 is also supported by the contrast between the cooperative/non-costly baseline scenario and Scenario 6 which involves the posting of a bond $\left(\mathrm{M}_{6}-\mathrm{M}_{2}=3.842 ; \mathrm{p}=.024\right)$. Bonds are also recognized as credible signals by managers in the study and result in greater trust relative to the cooperative but non-credible baseline. This result is again consistent with the emphasis on credibility in signaling theory. Jointly, Hypotheses 1 and 2 illustrate the importance of costliness - applied to either past cooperative behavior or conditional on future behavior.

Hypothesis 3 compares the cooperative/costly Scenario 1 with the bond in Scenario 6. The hypothesized null effect reverses the meaning of type-1 error. Hence, we follow Jöreskog and Sörbom (1989) and view the twotailed p-value as a goodness of fit indicator. The contrast yields a p-value of $.514\left(\mathrm{M}_{6}-\mathrm{M}_{1}=-1.263\right)$, suggesting a strong likelihood of an insignificant relationship, as hypothesized. Hence, while credibility matters, managers do not seem to distinguish between credible signals in the form of costly past behavior and credible signals created by bonds regulating incentives for future behavior. Thus, managers appear to be more calculative than posited in the non-calculative theories of trust, but less rational and less forward-looking than predicted by more calculative approaches (e.g., Williamson 1993). ${ }^{4}$

Hypothesis 4 considers the role of past history in the presence/absence of credible signals. It is supported by two contrasts. First, we compare the cooperative/non-costly baseline scenario with Scenario 7 in which a past history of cooperation between the firms is added. The contrast $\left(\mathrm{M}_{7}-\mathrm{M}_{2}=3.737 ; \mathrm{p}=.028\right)$ indicates that past history leads to higher trust in the non-credible regime. Turning to credible cooperation, we contrast the cooperative/costly Scenario 1 with Scenario 8, which is identical except for the addition of a past history between the firms. The two-tailed p-value of $.892\left(\mathrm{M}_{8}-\mathrm{M}_{1}=0.263\right)$ suggests a very strong likelihood of an insignificant relationship, as hypothesized. Hence, past history has no effect on trust when past behavior is credible. History only appears to matter when subjects are not offered recourse to credible signals.

Hypothesis 5 concerns the interpretation of non-cooperative behavior. It is supported by the contrast between Scenario 3 in which cooperation would have been costly and Scenario 4 where cooperation would not have been

\footnotetext{
${ }^{4}$ The fact that the bond produces lower trust further adds to the disconfirmation of the calculative view, beyond the insignificance of the coefficient.

60
} 
costly $\left(\mathrm{M}_{3}-\mathrm{M}_{4}=3.421 ; \mathrm{p}=.039\right)$. This supports the idea that costliness matters when evaluating non-cooperative behavior as well as cooperative behavior. In this case, non-cooperative behavior when cooperation would carry little cost is more indicative of a lack of trustworthiness than non-cooperative behavior when cooperation would carry a significant cost.

Finally, Hypothesis 6 is supported by the contrast between the cooperative/costly Scenario 1, in which the supplier is non-replaceable, and Scenario 5, which is identical except that the supplier is replaceable $\left(\mathrm{M}_{5}-\mathrm{M}_{1}=-\right.$ 5.632; $\mathrm{p}=.002)$. Replaceability reduces trust relative to the same scenario in which costly cooperative behavior is observed from a non-replaceable partner. Thus, replaceability appears to cause subjects to attribute cooperative behavior to incentives rather than type, thereby resulting in lower trust. Indeed, adding replaceability to credible past cooperation leads to no greater trust than in the baseline scenario $(\mathrm{p}=.768)$. This is especially interesting given the finding that the bond-another forward-looking and incentive-based mechanism-significantly increases trust relative to the baseline, per Hypothesis 2. As suggested above, entering into a bond is an observable action whereas replacement is created by external market forces. Subjects seem to place more weight on the action of committing to a bond than the more amorphous notion of replaceability imposed by the market. Thus, they again stop short of what would be expected from a fully calculative or rational perspective.

\section{Discussion}

The non-calculative trust literature emphasizes the importance of positive cooperative interactions as the basis of trust formation. This view has been criticized as myopic from an economic perspective by Williamson (1993) and others, with preference given to a consideration of incentives surrounding future exchanges. The contribution of this paper is to qualify extant non-calculative and calculative perspectives. Following signaling theory, we argue that cooperative actions in the past can lead to greater trust, but only to the extent that they are credible indicators of (cooperative) character or type by virtue of being costly.

The empirical study suggests that practicing managers attend to the credibility of past cooperative acts in a rational manner as suggested by signaling theory. Thus, non-calculative perspectives appear to fall short of an accurate description of trust formation and can be improved through a consideration of credibility. Yet managers do not appear to give any greater weight to incentives surrounding future exchanges as suggested by calculative approaches. Hence, the more calculative economic perspective is also inaccurate as a theory of trust formation. Indeed, market incentives created by low-cost replacement actually interfere with the development of trust rather than increasing it as would be expected from a calculative perspective.

Theoretically, the study demonstrates that beneficial past interactions are not sufficient for trust development. Only when past actions credibly indicate type do managers increase their level of trust in their partners. The exception to this is when an extended past history exists; in this case, we do find an increase in trust. However, past history does not appear to add to trust when recourse can be made to at least one past credible action. Hence, while we emphasize that history does matter in the study (in contrast to signaling theory itself) it is important only when credible signals are not available.

In addition to adding to the trust literature, the study adds to the signaling literature itself by examining the importance of credibility in the context of trust formation. As discussed above, economists have been reluctant to acknowledge trust and trustworthiness as enduring attributes of economic agents, in part because these factors run contrary to assumptions of self-interest seeking. Thus, the signaling literature has largely focused on hidden information related to more concrete and permanent aspects of individuals and firms such as product quality and individual abilities (as distinct from motivations). This study demonstrates that the principles of credibility extend to the domain of trust. Practicing managers consider the credibility of signals and also recognize trustworthiness as a legitimate and enduring (as evidenced by trust) aspect of character or type.

The fact that costliness and credibility matter also lends support to extant perspectives on trust that emphasize risk. While some authors see trust as a lubricant that in and of itself resolves potential conflicts between parties such that trust causes positive outcomes (Mayer et al. 1995), other authors place greater emphasis on trust as a risky action which opens a trusting party to potential vulnerabilities (Rosseau et al. 1998) and is thus relied upon in a discriminating manner. The fact that managers in the study match their level of trust to the credibility of the signals issued by their partners suggests that they appear to recognize such risk. Hence, they trust in a discriminating fashion only as warranted by the situation. 
The importance of costliness also explains the commonly observed phenomenon that "trying times" seem to lead to tighter bonds of trust between parties. Put differently, relationships emerge stronger following a "trial-by-fire" than before. Difficult circumstances will typically make cooperation costlier to one or both parties; hence this provides the right circumstances for credible signals to be sent and received, which result in greater trust.

Another interesting and novel finding concerns the contrast between the bond and market replacement forces. Presumably, these institutions should have very similar effects on expectations and trust, yet this is not observed in the study. Consistent with notions of bounded rationality, the results instead suggest that observable actions (actions that create, or enter parties into the bond) are more influential on trust than contextual factors external to actions in the relationship. Indeed, the results of the study are actually stronger; replaceability interferes with perceptions of trustworthiness by providing a competing explanation to type or character that for the practicing managers decreases their trust in the supplier. Hence, not only is replaceability not a strong driver of trust, it actually has a detrimental effect as it is perceived by the participants.

\section{References}

Akerloff, G. (1970). The market for lemons: quantitative uncertainty and markets mechanism. Quarterly Journal of Economics, 85.

Doz, Y. L. (1996). The evolution of cooperation in strategic alliances: Initial conditions or learning processes? Strategic management journal, 17(S1), 55-83.

Gambetta, D. (1988). Trust: Making and breaking cooperative relations.

Hosmer, L. T. (1995). Trust: The connecting link between organizational theory and philosophical ethics. Academy of management Review, 20(2), 379-403.

Jöreskog, K. G., \& Sörbom, D. (1989). LISREL 7: A guide to the program and applications. Spss.

Macneil, I. R. (1980). Economic analysis of contractual relations: Its shortfalls and the need for a rich classificatory apparatus. Nw. UL Rev., 75, 1018.

Macneil, I. R. (1982). The new social contract: An inquiry into modern contractual relations.

Mayer, R. C., Davis, J. H., \& Schoorman, F. D. (1995). An integrative model of organizational trust. Academy of management review, 20(3), 709-734.

McKnight, D. H., Cummings, L. L., \& Chervany, N. L. (1998). Initial trust formation in new organizational relationships. Academy of Management review, 23(3), 473-490.

Milgrom, P., \& Roberts, J. (1986). Price and advertising signals of product quality. Journal of political economy, 94(4), 796-821.

Mohr, J., \& Spekman, R. (1994). Characteristics of partnership success: partnership attributes, communication behavior, and conflict resolution techniques. Strategic management journal, 15(2), 135-152.

Moran, P. (2005). Structural vs. relational embeddedness: Social capital and managerial performance. Strategic management journal, 26(12), 1129-1151.

Nelson, P. (1974). Advertising as information. Journal of political economy, 82(4), 729-754.

Poppo, L., \& Zenger, T. (2002). Do formal contracts and relational governance function as substitutes or complements? Strategic management journal, 23(8), 707-725.

Radner, R. (1981). Monitoring cooperative agreements in a repeated principal-agent relationship. Econometrica: Journal of the Econometric Society, 1127-1148.

Ring, P. S., \& Van de Ven, A. H. (1992). Structuring cooperative relationships between organizations. Strategic management journal, 13(7), 483-498.

Ring, P. S., \& Van de Ven, A. H. (1994). Developmental processes of cooperative interorganizational relationships. Academy of management review, 19(1), 90-118.

Ross, S. A. (1973). The economic theory of agency: The principal's problem. The American Economic Review, 63(2), 134-139.

Rothschild, M., \& Stiglitz, J. (1978). Equilibrium in competitive insurance markets: An essay on the economics of imperfect information. In Uncertainty in economics (pp. 257-280).

Rousseau, D. M., Sitkin, S. B., Burt, R. S., \&Camerer, C. (1998). Not so different after all: A cross-discipline view of trust. Academy of management review, 23(3), 393-404.

Sako, M. (1992). Price, quality and trust: Inter-firm relations in Britain and Japan (No. 18). Cambridge University Press. 
Sako, M., \& Helper, S. (1998). Determinants of trust in supplier relations: Evidence from the automotive industry in Japan and the United States. Journal of Economic Behavior \& Organization, 34(3), 387-417.

Sitkin, S. B., \& Roth, N. L. (1993). Explaining the limited effectiveness of legalistic "remedies" for trust/distrust. Organization science, 4(3), 367-392.

Spence, M. (1973). Job Market Signaling. The Quarterly Journal of Economics, 87(3), 355-374.

Stigler, G. J. (1961). The economics of information. Journal of political economy, 69(3), 213-225.

Wang, S., Beatty, S. E., \& Foxx, W. (2004). Signaling the trustworthiness of small online retailers. Journal of interactive marketing, 18(1), 53-69.

Williamson, O. E. (1985). The Economic Institutions of Capitalism: Firms, markets, relational Contracting. Free Press.

Williamson, O. E. (1993). Calculativeness, trust, and economic organization. The journal of law and economics, 36(1, Part 2), 453-486.

Zaheer, A., McEvily, B., \&Perrone, V. (1998). Does trust matter? Exploring the effects of interorganizational and interpersonal trust on performance. Organization science, 9(2), 141-159.

Zucker, L. G. (1986). Production of trust: Institutional sources of economic structure, 1840-1920. Research in organizational behavior.

\section{APPENDIX Scenario Descriptions}

\section{Task Introduction}

Please consider the following situation:

Suppose that you are a purchasing manager in charge of sourcing components from external suppliers. Your firm has a number of different suppliers. You often ask suppliers to make changes to the component they supply to your firm to improve your firm's performance. Some suppliers are highly cooperative in making changes and helping your firm, while others are less cooperative and may even refuse to make changes.

It is important for you to determine the type of supplier you are dealing with: trustworthy or untrustworthy. This is especially important in new relationships where you have not yet asked the supplier to make any changes, and you therefore do not know how the supplier is likely to respond.

On the following pages you will read about the behavior of several different suppliers. In each case, your firm has just made a request to the supplier to make changes to the component they supply to your firm. You will read about the implications of your request on the supplier's profits and the supplier's response to your request.

After each scenario, we will ask you to evaluate the type of supplier you are dealing with. You may indicate that you think the supplier is highly trustworthy, highly untrustworthy, or somewhere in-between. Please give your honest judgement in each case. Remember, each of the following scenarios concerns a different supplier.

\section{Scenario 1 [COOPERATIVE; COSTLY; NON-REPLACEABLE; NO HISTORY]}

You recently asked this supplier to make a change to the component it supplies to your firm. The change would cost the supplier $\$ 150,000$ to make. The supplier's revenues would increase $\$ 100,000$ as a result of increased sales of your product if it makes the change. The supplier is the only firm that can supply the component. In response to your request, the supplier agrees to make the change. Please indicate what type of supplier you think you are dealing with in this scenario:

\section{Scenario 2 [COOPERATIVE; NON-COSTLY; NON-REPLACEABLE; NO HISTORY]}

You recently asked this supplier to make a change to the component it supplies to your firm. The change would cost the supplier $\$ 100,000$ to make. The supplier's revenues would increase $\$ 150,000$ as a result of increased sales of your product if it makes the change. The supplier is the only firm that can supply the component. In response to your request, the supplier agrees to make the change. Please indicate what type of supplier you think you are dealing with in this scenario:

\section{Scenario 3 [NON-COOPERATIVE; COSTLY; NON-REPLACEABLE; NO HISTORY]}

You recently asked this supplier to make a change to the component it supplies to your firm. The change would cost the supplier $\$ 150,000$ to make. The supplier's revenues would increase $\$ 100,000$ as a result of increased sales of your product if it makes the change. The supplier is the only firm that can supply the component. In 
response to your request, the supplier refuses to make the change. Please indicate what type of supplier you think you are dealing with in this scenario:

\section{Scenario 4 [NON-COOPERATIVE; NON-COSTLY; NON-REPLACEABLE; NO HISTORY]}

You recently asked this supplier to make a change to the component it supplies to your firm. The change would cost the supplier $\$ 100,000$ to make. The supplier's revenues would increase $\$ 150,000$ as a result of increased sales of your product if it makes the change. The supplier is the only firm that can supply the component. In response to your request, the supplier refuses to make the change. Please indicate what type of supplier you think you are dealing with in this scenario:

\section{Scenario 5 [COOPERATIVE; COSTLY; REPLACEABLE; NO HISTORY]}

You recently asked this supplier to make a change to the component it supplies to your firm. The change would cost the supplier $\$ 150,000$ to make. The supplier's revenues would increase $\$ 100,000$ as a result of increased sales of your product if it makes the change. If the supplier refused to make the change, you could move your business to any one of a number of other suppliers. In response to your request, the supplier agrees to make the change. Please indicate what type of supplier you think you are dealing with in this scenario:

\section{Scenario 6 [COOPERATIVE; BOND; NON-REPLACEABLE; NO HISTORY]}

You recently asked this supplier to make a change to the component it supplies to your firm. The change would cost the supplier $\$ 100,000$ to make. The supplier's revenues would increase $\$ 150,000$ as a result of increased sales of your product if it makes the change. However, this increase in revenue will occur only if the supplier is cooperative in making future changes. Otherwise, the market will not permanently support your product and the supplier's revenue would increase by only $\$ 50,000$. The supplier is the only firm that can supply the component. In response to your request, the supplier agrees to make the change. Please indicate what type of supplier you think you are dealing with in this scenario:

\section{Scenario 7 [COOPERATIVE; NON-COSTLY; NON-REPLACEABLE; HISTORY]}

You recently asked this supplier to make a change to the component it supplies to your firm. The change would cost the supplier $\$ 100,000$ to make. The supplier's revenues would increase $\$ 150,000$ as a result of increased sales of your product if it makes the change. The supplier is the only firm that can supply the component. In response to your request, the supplier agrees to make the change. With this particular supplier, you have made requests identical to the one above on five separate occasions. In each case, the supplier has agreed to make the change. Please indicate what type of supplier you think you are dealing with in this scenario:

\section{Scenario 8 [COOPERATIVE; COSTLY; NON-REPLACEABLE; HISTORY]}

You recently asked this supplier to make a change to the component it supplies to your firm. The change would cost the supplier $\$ 150,000$ to make. The supplier's revenues would increase $\$ 100,000$ as a result of increased sales of your product if it makes the change. The supplier is the only firm that can supply the component. In response to your request, the supplier agrees to make the change. With this particular supplier, you have made requests identical to the one above on five separate occasions. In each case, the supplier has agreed to make the change. Please indicate what type of supplier you think you are dealing with in this scenario: 